Published in final edited form as:

Clin Geriatr Med. 2007 August ; 23(3): 615-viii. doi:10.1016/j.cger.2007.03.003.

\title{
Herpes zoster
}

\section{Kenneth Schmader, M.D.}

Center for the Study of Aging and Human Development and Division of Geriatrics, Department of Medicine, Duke University Medical Center; and Geriatric Research, Education and Clinical Center (GRECC), Durham Veterans Affairs Medical Center, Durham, North Carolina, USA.

\section{Synopsis}

Herpes zoster afflicts millions of older adults annually worldwide and causes significant suffering due to acute and chronic pain, or postherpetic neuralgia (PHN). Herpes zoster is caused by the reactivation of varicella-zoster virus $(\mathrm{VZV})$ in sensory ganglia in the setting of age, disease and drug-related decline in cellular immunity to VZV. VZV-induced neuronal destruction and inflammation causes the principal problems of pain, interference with activities of daily living and reduced quality of life in older adults. To address these problems, the optimal treatment of herpes zoster requires early antiviral therapy and careful pain management. For patients who develop PHN, evidence-based pharmacotherapy using topical lidocaine patch, gabapentin, pregabalin, tricyclic antidepressants, and/or opiates can reduce pain burden. The live attenuated zoster vaccine is effective in reducing pain burden and preventing herpes zoster and PHN in older adults.

\section{Keywords}

Herpes zoster; varicella-zoster virus; postherpetic neuralgia; elderly; aged

\section{Introduction}

Herpes zoster is a neurocutaneous disease that is caused by the reactivation of varicellazoster virus (VZV) from a latent infection of dorsal sensory or cranial nerve ganglia following primary infection with VZV earlier in life. VZV is a double-stranded DNA herpesvirus with a genome that contains at least 70 gene products (1). VZV expresses gene products and attempts replication throughout life but cellular immunity is critical to containing VZV. With aging-related decline in cellular immunity to VZV, the virus may escape cell-mediated immune containment and spread in the affected ganglia and sensory nerves to the skin.

\footnotetext{
Address correspondence to Dr. Schmader at 182 GRECC, Durham Veterans Affairs Medical Center, Durham, North Carolina, USA, telephone: 919-286-6932, fax: 919-286-6823, kenneth.schmader@ duke.edu.

Publisher's Disclaimer: This is a PDF file of an unedited manuscript that has been accepted for publication. As a service to our customers we are providing this early version of the manuscript. The manuscript will undergo copyediting, typesetting, and review of the resulting proof before it is published in its final citable form. Please note that during the production process errors may be discovered which could affect the content, and all legal disclaimers that apply to the journal pertain.
} 


\section{Epidemiology}

The estimated incidence of herpes zoster in persons older than 65 years old varies from approximately 10 to 14 cases per 1000 per year (2-4). The lifetime incidence of herpes zoster is estimated to be about $20-30 \%$ in the general population and maybe as high as $50 \%$ among those surviving to 85 years or higher (5). Current population figures and herpes zoster incidence data yield estimates of about 1 million new cases of herpes zoster each year in the United States (6). The incidence of recurrent herpes zoster is not as well established but the frequency of recurrent events is higher in immune compromised individuals $(7,8)$. In one study, the frequency of recurrent herpes zoster was $5.7 \%$ among immune competent individuals (7)

The strongest risk factors for herpes zoster are aging and suppression of cellular immunity. The increase in the likelihood of herpes zoster with aging starts around 50 to 60 years of age and increases into late life in individuals older than 80 years of age $(2,3)$.

Immunocompromised patients at risk for herpes zoster include persons with human immunodeficiency virus (HIV) infection, Hodgkin's disease, non-Hodgkin's lymphomas, leukemia, bone marrow and other organ transplants, systemic lupus erythematosus, rheumatoid arthritis, and those individuals taking immunosuppressive medications, including tumor necrosis factor inhibitors $(5,6,9)$. Other risk factors include white race, female sex, and physical trauma $(5,10,11)$. The childhood varicella vaccination program in the US does not appear to have affected the incidence of herpes zoster (12).

Patients with herpes zoster who have a vesicular rash may transmit VZV via direct contact, airborne or droplet nuclei to seronegative, non-immune individuals (13). These individuals may then develop varicella usually within 10-21 days after contact with a case. In one study of school and day care settings, of $290 \mathrm{HZ}$ cases reported, 27 (9\%) resulted in 84 secondary varicella cases (13). If the rash is only maculopapular or crusted, there is no danger of VZV transmission. Important groups at risk for varicella from contact with herpes zoster patients include children who have not received the varicella vaccine or who have had an insufficient response to the vaccine, and susceptible health care workers and staff in hospital or in nursing homes particularly if they are pregnant or immunocompromised. The exposure of a latently infected individual to herpes zoster does not cause herpes zoster or varicella. Nearly all older adults are latently infected with VZV.

\section{Clinical Features}

VZV reactivation and spread in the affected sensory ganglion and peripheral sensory nerve evokes a cellular immune response and neuronal inflammation and destruction (6). Before VZV reaches the skin, the patient experiences prodromal sensations in the affected dermatome such as aching, burning, or lancinating pain, or itching or tingling. Prodromal symptoms baffle patients and physicians alike by imitating other painful conditions in older persons (i.e., migraine headaches, trigeminal neuralgia, myocardial infarction, cholecystitis, biliary or renal colic, appendicitis, lumbosacral strain, "pulled" muscles etc.). One clue to incipient herpes zoster is very sensitive skin in the affected dermatome before the rash breaks out. The prodrome usually lasts a few days. VZV may not reach the skin in some 
patients which results in a unilateral, dermatomal neuralgia without a rash. This condition is known as zoster sine herpete.

Once VZV invades the dermis and epidermis, the rash appears and reveals the reason for the patient's pain or discomfort. The rash is unilateral, dermatomal, red, maculopapular and usually develops vesicles (Figure 1). It is not uncommon for patients to develop lesions in adjacent dermatomes. The rash generally starts crusting over in a week to 10 days, and heals within 2-4 weeks. Atypical rashes may occur in older persons. The rash may be limited to a small patch located within a dermatome or may remain maculopapular without ever developing vesicles. Conversely, vesicles may form for several days and involve several dermatomes.

VZV-induced acute neuritis produces unilateral dermatomal neuralgic pain in many older adults, although a few patients never develop pain while others may experience the delayed onset of pain days or weeks after rash onset. The neuritis is described as burning, deep aching, tingling, itching, or stabbing. A subset of patients may develop severe pain, especially those with trigeminal nerve involvement. Acute herpetic neuralgia has a profound negative impact on functional status and quality of life and usually results in substantial health service utilization $(14,15)$.

In general, the number of older herpes zoster patients with pain decreases over weeks to months from rash onset. Unfortunately, a significant number of older persons with herpes zoster continue to experience pain for months after the acute phase of the illness and therefore develop PHN. Increasing age is the strongest risk factor for PHN (16). The PHN patient may suffer from constant pain ("burning, aching, throbbing"), intermittent pain ("stabbing, shooting") and stimulus-evoked pain such as allodynia ("tender"). Allodynia, the experience of pain after a non-painful stimulus, is a particularly disabling component of the disease. Patients with allodynia suffer from severe pain after the lightest touch of the affected skin by things as trivial as a cold wind or a piece of clothing. These subtypes of pain may produce chronic fatigue, disordered sleep, depression, anorexia, weight loss and social isolation. Furthermore, PHN can impair the elderly patient's functional status by interfering with basic ADLs such as dressing, bathing and mobility and instrumental ADLs such as traveling, shopping, cooking, and housework.

Herpes zoster involving the ophthalmic division of the trigeminal nerve in may cause serious ocular complications. The likelihood of inflammation of the eye appears to be higher when the rash is on the tip of the nose (nasociliary branch involvement) but in general the appearance and location of the facial rash does not predict the presence or extent of eye involvement. VZV-induced damage to the cornea and uvea and other eye structures can cause corneal anesthesia and ulceration, glaucoma, optic neuritis, eyelid scarring and retraction, visual impairment, and blindness in patients who did not receive antiviral therapy.

Other less frequent but important complications of herpes zoster in older adults include stroke secondary to granulomatous arteritis of the internal carotid artery in ophthalmic herpes zoster; focal motor paresis in muscles served by nerve roots of the corresponding affected dermatome; disordered balance, hearing and facial paresis in cranial neuritis 
(Ramsay-Hunt syndrome); meningoencephalitis; and secondary bacterial infection of the $\operatorname{rash}(6)$.

\section{Diagnosis}

Herpes zoster may be diagnosed clinically with high confidence when the characteristic unilateral, dermatomal, vesicular rash and neuralgic pain presents in an older patient. The main source of diagnostic error is herpes simplex virus (HSV) infection (6). Features that may distinguish HSV from herpes zoster include multiple recurrences, especially around the genitals or mouth, and the absence of chronic pain. However, it may be impossible to distinguish the two conditions on clinical grounds because HSV presents with a unilateral, red, maculopapular, vesicular rash and acute pain similar to herpes zoster. The differential diagnosis also includes contact dermatitis, burns, and vesicular lesions associated with fungal infections but the history and examination usually makes the distinction clear.

Herpes zoster should be diagnosed using laboratory diagnostic testing when differentiating herpes zoster from HSV infection is difficult, for suspected organ involvement, and for atypical presentations, particularly in the immunocompromised host. The best diagnostic test is polymerase chain reaction (PCR) because of its very high sensitivity and specificity (17). Vesicle fluid is the best specimen for PCR analysis. Lacking vesicle fluid, acceptable specimens include lesion scrapings, crusts, tissue biopsy, or cerebrospinal fluid for the first three techniques.

\section{Treatment}

\section{Acute Herpes zoster}

General Principles-The main goal of the treatment of herpes zoster in older adults is the reduction or elimination of acute pain and the prevention of PHN. It is important to understand that the impact of herpes zoster on functional status, mood, and quality of life in older adults is directly related to pain intensity. Education and counseling about herpes zoster reduce anxiety and misunderstandings about the disease. Questions about the duration of pain and transmission of VZV are common. Social support, mental and physical activity, adequate nutrition, and a caring attitude help patients cope with the illness. Treatment adherence and response may be altered in older adults who are living alone, cognitively impaired, frail, or coping with recent negative life events.

Antiviral therapy-Acyclovir, famciclovir, and valacyclovir are nucleoside analogues that effectively treat VZV infections (Table 1)(6). These agents are phosphorylated by viral thymidine kinase and cellular kinases to a triphosphate form that interferes with viral DNA synthesis by inhibiting viral DNA polymerase. Valacyclovir and famciclovir are prodrugs that are better absorbed than acyclovir following oral administration which results in much higher blood levels of antiviral activity.

Multiple randomized controlled trials demonstrated that oral acyclovir $(800 \mathrm{mg}$ five times a day for 7 days), famciclovir (500 $\mathrm{mg}$ every 8 hours for 7 days) and valacyclovir (1 gm three times a day for 7 days) reduce acute pain and the duration of chronic pain in older herpes 
zoster patients who are treated within 72 hours of rash onset $(6,18)$. The most common adverse effects are nausea, vomiting, diarrhea, and headache. No head to head study has shown superiority of one of these agents over another so all three agents are acceptable. Because of their superior pharmacokinetics and simpler dosing schedule, famciclovir or valacyclovir are preferred to acyclovir for oral therapy of VZV infections. The benefits of treating herpes zoster patients who present more than 72 hours after rash onset are unknown. Some experts recommend antiviral therapy for patients presenting more than 72 hours after rash onset with continued new vesicle formation or when there are cutaneous, motor, neurologic, or ocular complications. Unfortunately, 20-30\% of treated patients in antiviral trials had pain 6 months from herpes zoster onset. These data indicate that even optimally treated patients can develop PHN.

Ophthalmic herpes zoster is important in older patients because of the risk of visual impairment or blindness in persons who may already have compromised vision from other age-related pathology such as glaucoma, macular degeneration, cataracts or diabetic neuropathy. Oral acyclovir, famciclovir and valacyclovir are effective for the prevention of ocular complications from ophthalmic herpes zoster. Ophthalmologist consultation is recommended in older patients with ophthalmic herpes zoster to determine the presence and extent of ocular involvement and to determine the utility of local treatments such as mydriatics, glucocorticoids, or topical antivirals.

Analgesics-Acute herpes zoster pain management requires the same principles as managing any pain: use of standardized pain measures, scheduled analgesia, and consistent and frequent follow-up to adjust dosing to the needs of the patient. The choice of treatment will be contingent on the patient's comorbidities, concurrent medications, pain intensity and preferences.

Patients with mild pain may be managed with acetaminophen or non-steroidal agents. Patients with moderate to severe pain usually require treatment with a strong opioid analgesic (e.g., oxycodone)(19). There are a number of approaches to using short or longacting opioids in the treatment of herpes zoster pain. One commonly used approach is to start with a short-acting medication at an oxycodone equianalgesic dosage of $5 \mathrm{mg}$ four times daily and titrating the dose until pain reduction or intolerable adverse effects (19). If an effective and tolerable dose is found, then treatment can be switched from a short-acting to a long-acting medication depending on cost and patient preference. Long-acting medications are more convenient and may also provide a more consistent level of pain relief. Rescue doses of a short-acting opioid can be used for exacerbations of pain as needed with the long-acting opioid. Opioids have multiple adverse effects including nausea, constipation and sedation which may be intolerable in some older adults. In most cases, constipation should be anticipated and managed with laxative therapy.

Corticosteroids-Randomized controlled trials of corticosteroids versus placebo or acyclovir with or without corticosteroids in older herpes zoster patients showed equal rates of PHN (20-22). These findings argue against the routine use of corticosteroids in older herpes zoster patients. In most trials, corticosteroids reduced acute herpes zoster pain although that beneficial effect was not sustained. In the a trial of acyclovir and prednisone, 
time to uninterrupted sleep, return to daily activity and cessation of analgesic therapy was significantly accelerated in patients who received corticosteroids (22). However, the patients in the trial had an average age of 60 years old and no relative contraindications to corticosteroids such as hypertension, diabetes mellitus or osteoporosis. In the trial, prednisone was administered orally at $60 \mathrm{mg} /$ day for days 1 to $7,30 \mathrm{mg}$ /day for days 8 to 14 , and $15 \mathrm{mg} /$ day for days 15 to 21 . The most common adverse effects of short term prednisone use are gastrointestinal symptoms (dyspepsia, nausea, vomiting), edema and granulocytosis. Some clinicians use corticosteroids for VZV-induced facial paralysis and cranial polyneuritis to improve motor outcomes, reduce peripheral nerve damage from foraminal compression, and reduce pain. If corticosteroid treatment is considered, it should always be used with antiviral therapy.

Adjuvant agents-If moderate-to-severe herpes zoster pain is inadequately relieved by antiviral agents in combination with oral analgesic medications and/or corticosteroids, then other therapies to consider include gabapentin or pregabalin or neural blockade. None of these approaches have been shown to prevent PHN but they may be useful in reducing acute pain.

A single $900 \mathrm{mg}$ dose of gabapentin has been shown to reduce acute herpes zoster pain over a 6 hour period (23). However, neither gabapentin nor pregabalin have been shown to prevent PHN or provide significant acute herpes zoster pain relief in randomized controlled trials (19). If used, recognize that gabapentin and pregabalin can cause sedation, dizziness, ataxia and peripheral edema. It is best to give starting doses at bedtime and carefully increase subsequent doses to three times daily for gabapentin and twice daily for pregabalin.

If pain control from antiviral agents and analgesics with or without any of the adjuvant drugs noted above is inadequate then anesthetic nerve blocks should be considered. This intervention will require referral to a pain specialist. A randomized controlled trial of antiviral therapy, oral analgesics, and a single epidural block with bupivacaine and methylprednisolone compared to antiviral therapy and oral analgesics alone showed that neural blockade reduces acute pain but does not prevent PH (24).

\section{Postherpetic Neuralgia}

General Principles-The main goal of the treatment of PHN in older adults is the reduction of pain and associated symptoms including depression, insomnia, fatigue, and functional impairment. No one treatment is uniformly and completely effective in all older PHN patients. Therefore, it is important to set realistic goals with the patient. Specifically, the patient needs to know that it is unlikely that any one single intervention will take the pain away completely but some interventions are likely to reduce pain while balancing the risk of potential adverse effects. Persons affected by PHN need to understand that the natural history of PHN is one of improvement over weeks, months and even years regardless of the underlying treatment in many patients. The same comments in the section on herpes zoster treatment regarding pain management apply to the PHN patient as do comments regarding social support, mental and physical activity, adequate nutrition, and a caring attitude. 
Pharmacotherapy-The topical lidocaine patch, gabapentin, pregabalin, opioids, tricyclic antidepressants (TCAs), tramadol and topical capsaicin are considered evidence based therapies because one or more randomized controlled trials demonstrated efficacy and relative safety with these agents (25). Gabapentin, pregabalin, the topical lidocaine patch 5\% and topical capsaicin patch $8 \%$ are approved by the FDA for the treatment of PHN. Opioids and TCAs are not approved by the FDA partly because the manufacturers of these products have not sought FDA approval. Pharmacotherapy for neuropathic pain, including PHN, is discussed in more detail in recently published summaries (25-27). In general, these agents produce clinically significant reduction in pain in about 30-60\% of patients. Unfortunately there is no good way to predict which patient will respond or not respond to a given drug. Furthermore, there are few head to head comparisons of these drugs so it is unknown if one agent is clearly superior in efficacy to another. Clinical information about these drugs is summarized in Table 2. Remember that starting doses and maximum doses of drugs are generally lower in frail older adults. The upward titration of drug doses often needs to be slower in frail older adults as well.

The initial choice of agent depends on the patient's comorbidities and preferences as well as cost and formulary restrictions. The topical lidocaine patch, gabapentin and pregabalin are generally better tolerated than opioids and TCAs in older adults. The topical lidocaine patch is easy to use, gives initial pain relief in hours to days when effective (two weeks for an adequate trial) but can produce a skin rash that prevents use of the patch. Gabapentin has few drug interactions, gives initial pain relief in days to weeks when effective (adequate trial requires 3-8 weeks for titration plus 1-2 weeks at maximum tolerated dosage) but can produce somnolence, dizziness, and peripheral edema. These adverse effects require monitoring and possibly dosage adjustment but usually not treatment discontinuation. Gabapentin may cause or exacerbate gait and balance problems and cognitive impairment in the frail elderly which can require discontinuation of therapy. Pregabalin has few drug interactions, has a more rapid onset of action than gabapentin, gives initial pain relief within one to two days when effective but also produces the same adverse effects as gabapentin.

Opioids give initial pain relief in hours to days when effective (adequate trial requires 4 weeks) but the well known adverse effects of opioids will preclude their use in some older adults. Opioid analgesics must be used very cautiously in patients with a history of substance abuse. The risk that substance abuse will develop in patients who do not have a history of substance abuse is thought to be low in the older patient with PHN. Tramadol gives initial pain relief in hours to days when effective (adequate trial requires 4 weeks) but has similar adverse effects as opioids because a major metabolite is a mu opioid agonist. Tramadol is associated with an increased risk of seizures in patients who have a history of seizures or use drugs that can reduce the seizure threshold and serotonin syndrome in patients who use serotonergic medications, especially selective serotonin reuptake inhibitors (SSRI).

Nortriptyline gives initial pain relief in several days to weeks when effective (adequate trial requires 6-8 weeks with at least 1-2 weeks at maximum tolerated dosage) but has several potentially significant anticholinergic and cardiac adverse effects in older adults. A screening EKG to check for cardiac conduction abnormalities is recommended before 
beginning any TCA treatment in the elderly. TCAs are contraindicated in patients with QT prolongation or familial histories of long-QT syndromes, with atrioventricular block or bundle-branch block and with a recent acute myocardial infarction. Although amitriptyline was tested in many PHN trials it is often poorly tolerated in older adults because of its much higher anticholinergic activity. Nortriptyline has equivalent efficacy compared to amitriptyline in PHN but is better tolerated (28). Desipramine is a reasonable alternative to nortriptyline. In a crossover study of PHN comparing opioid analgesics, TCAs, and placebo, controlled-release morphine and TCAs provided significant benefits on pain (29). In this trial, patients preferred treatment with opioid analgesics compared to TCAs and placebo but there was a greater incidence of adverse effects and drop-outs during opioid treatment.

Topical capsaicin is available in creams, gels or lotions in concentrations from $0.025 \%$, $0.075 \%$ and $0.25 \%$ and as an $8 \%$ patch. The burning from capsaicin makes it difficult to tolerate for many patients. Nonetheless, topical capsaicin maybe considered as a back-up therapeutic option in PHN because there may be some individuals who tolerate it. The patch requires application in a clinic by personnel who are trained on how to properly apply and monitor it.

Non-response to single drug therapy often leads to combination therapy with one or more of the above agents but there are few data regarding the additive or synergistic benefits of combination treatment. The potential advantages of combination therapy include augmentation of a partial response to a single drug, more rapid effect when a medication that requires titration to reach an effective dosage is also being used, and better analgesia at lower doses of drug. The potential disadvantages of combination therapy in older adults include an increased risk of adverse effects as the number of medications is increased, the difficulty determining which medication is responsible for adverse effects, and increased cost. In a randomized, controlled trial of the effects of morphine alone, gabapentin alone or morphine-gabapentin combination on neuropathic pain that included patients with PHN, gabapentin and morphine combined achieved modestly better pain relief at lower doses of each drug than either as a single agent (30). However, the combination was associated with higher levels of sedation, dry mouth, and cognitive dysfunction than the maximal tolerated dose of each single agent. In a similar randomized, controlled trial of the effects of nortriptyline alone, gabapentin alone or nortriptylinegabapentin combination on neuropathic pain that included patients with PHN, gabapentin and nortriptyline combined achieved modestly better pain relief at lower doses of each drug than either as a single agent.

However, the combination was associated with higher levels of dry mouth than the maximal tolerated dose of each single agent (31).

Other treatments-Some older patients with PHN will not have an adequate response to any of the front line medications. For these patients, other drug and non-drug treatments deserve consideration. Patients who require complex drug combinations, risky second line medications or invasive treatments should be referred to a pain management center. A detailed review of these interventions is beyond the scope of this chapter but non-drug noninvasive and invasive treatments will be briefly summarized. 
Non-invasive treatments include physical modalities such as cold application or transcutaneous electrical nerve stimulation (TENS), percutaneous electrical nerve stimulation (PENS), psychological treatments and acupuncture. These interventions have little risk and may be useful in some patients but whether they are effective in a population of patients with PHN is unknown and needs to be tested in controlled clinical trials. Some PHN patients may have associated myofascial pain in addition to neuropathic pain (32). The presence of myofascial pathology is indicated by taut muscle bands (i.e., a group of tense muscle fibers extending from a trigger point to the muscle attachments) and trigger point(s) (i.e., a hyperirritable spot in skeletal muscle that is painful on compression) in the affected dermatome. These patients are good candidates for a trial of PENS.

Invasive treatments may be considered when patients have failed to obtain adequate relief from non-invasive treatment approaches. Invasive treatments include peripheral and central neural blockade, central nervous system (CNS) drug delivery, spinal cord stimulation and neurosurgical techniques. Neural blockade techniques include sensory nerve, plexus, and sympathetic nerve blocks as well as epidural and intrathecal blockade with lidocaine-like drugs and/or corticosteroids. Many PHN patients note initial relief of pain with nerve blocks but few experience long lasting relief. Central nervous system drug delivery attempts to place drug (e.g., morphine), as close as possible to central pain receptors in the spinal cord corresponding to the affected dermatome(s). Spinal cord stimulation requires implantation of an electrode in the thoracic or lumbar epidural space and the placement of a percutaneous electrical stimulator. These interventions represent rational approaches to pain relief but they have not been proven effective in controlled trials, partly because the design and conduct of such trials are difficult, and they carry procedural risks in the elderly. In general, these interventions have a limited role in PHN treatment and should be contemplated in patients who have failed all other treatments and continue to have disabling pain.

\section{Prevention}

\section{Live Attenuated Zoster Vaccine}

The live attenuated zoster vaccine significantly boosts VZV-specific cellular immunity in older adults which provides the scientific rationale for using the vaccine because cellular immunity to VZV declines with age (33). The clinical rationale for the zoster vaccine lies in the facts that herpes zoster causes substantial morbidity, antiviral therapy does not prevent PHN and must be initiated within 72 hours of rash onset for maximum benefit, and PHN treatments are incompletely effective and often poorly tolerated by older adults.

The efficacy of the live attenuated zoster vaccine in reducing the incidence and severity of herpes zoster in older adults was demonstrated in the Shingles Prevention Study (33). The Shingles Prevention Study was a randomized, double-blind, placebo controlled trial involving 38,546 community-dwelling persons $¥ 60$ years old who were followed them for herpes zoster and adverse events for a median of three years after receiving vaccine or placebo. The vaccine reduced incidence of herpes zoster from 11.12 to 5.42 cases (51.3\%) per 1000 person-years for an NNT of 59 over the 3.12 years of the study. The vaccine reduced the incidence PHN from 1.38 to 0.46 cases $(66.5 \%)$ per 1000 person years for an NNT of 362 over the duration of the study. The zoster vaccine also reduced the pain burden 
of illness (a pain severity by duration measure) caused by herpes zoster by $61.1 \%$. Two large cohort studies of the use of zoster vaccine in "real world" practice settings showed very similar results for vaccine efficacy for incidence of herpes zoster $(34,35)$. The zoster vaccine also reduces interference with herpes zoster-related functional impairments and health-related quality of life (36). In addition, the zoster vaccine appears to reduce the incidence of herpes zoster in vaccines who later undergo chemotherapy (37). Reactions at the injection site are more frequent among vaccine recipients but are generally mild. The results of pre- and post-licensure studies indicate that the vaccine is generally safe and well tolerated $(38,39)$.

The Advisory Committee on Immunization Practices (ACIP) of the CDC recommends the live attenuated zoster vaccine for the prevention of herpes zoster and PHN in immuncompetent adults 60 years of age and older (5). Anaphylactic reactions to gelatin or neomycin; with leukemia, lymphomas, or other malignant neoplasms affecting the bone marrow or lymphatic system; on immunosuppressive therapy, including high-dose corticosteroids ( $\geq 20 \mathrm{mg} /$ day of prednisone or equivalent) lasting two or more weeks; with AIDS or other clinical manifestations of HIV, including persons with CD4+ T-lymphocyte values $\mathcal{S} 00$ per $\mathrm{mm}^{3}$ undergoing hematopoietic stem cell transplantation (HSCT) or receiving recombinant human immune mediators and immune modulators are contraindications to the live attenuated zoster vaccine. The live attenuated zoster vaccine can be given simultaneously with other inactivated vaccines including influenza, pneumococcal polysaccharide and pneumococcal conjugate vaccines (5).

The exact duration of the protection against herpes zoster by the zoster vaccine is unknown. In the Short Term Persistence Substudy of the Shingles Prevention Study, 7320 vaccine and 6950 placebo recipients were followed through year 7 after vaccination (40). Vaccine efficacy for herpes zoster and pain burden persisted through year 5 after vaccination. In the Long Term Persistence Substudy of the Shingles Prevention Study, 6867 subjects were followed up to 11 years after vaccination and compared to historical controls. Vaccine efficacy for herpes zoster and pain burden persisted through year 8 after vaccination (41). Currently, there is no recommendation for a booster dose of the vaccine.

The efficacy of the live attenuated zoster vaccine in 50-59 year old individuals was demonstrated in a large randomized placebo controlled trial which showed vaccine efficacy of $69.8 \%$ (42). The FDA licensed the vaccine for use in immunocompetent adults 50 years of age and greater based on the results of this trial. However, The ACIP retained the recommendation to vaccinate at 60 years of age and over because zoster vaccine administration should be timed to achieve the greatest reduction in burden of herpes zoster and its complications, which is in persons over 60 years old (43). Given that there is insufficient evidence for long term protection offered by the herpes zoster vaccine, persons vaccinated under 60 years of age may not be protected when the incidence of herpes zoster and its complications are highest. Conversely, neither the FDA nor the ACIP set an upper age limit on the use of the vaccine. These individuals are at highest risk for herpes zoster and PHN and reduction of herpes zoster pain severity and duration occurs in the "old-old" even when herpes zoster is not prevented. 
The efficacy of the zoster vaccine in individuals who have already had herpes zoster is unknown. However, older adults with prior herpes zoster ask for the vaccine because they don't want to experience zoster again and herpes zoster recurs in immune competent individuals. The ACIP recommends the zoster vaccine for persons older than 60 years of age whether or not they report a prior episode of herpes zoster.

\section{Subunit Adjuvanted Zoster Vaccine}

A recently developed subunit zoster vaccine containing VZV glycoprotein E and the AS01b adjuvant system (called HZ/su) showed a strong immune response and a clinically acceptable safety profile in phase I and II studies (44). VZV glycoprotein E is an important antigen target in the cellular immune response to VZV and it plays a role in VZV replication and spread. The AS01B adjuvant system stimulates CD4+ T-cell and humoral immune responses against recombinant proteins.

The subunit adjuvanted zoster vaccine was tested for efficacy against herpes zoster in a multisite randomized placebo controlled trial called the Zoster Efficacy Study in Adults 50 Years of Age or Older (ZOE-50)(44). A total of 15,411 participants received the vaccine $(\mathrm{n}=7698)$ or placebo ( $\mathrm{n}=7713$ participants). The participants were stratified by age groups (50 to 59, 60 to 69 , and $\geq 70$ years). The intervention was two intramuscular doses of the vaccine or placebo 2 months apart. The mean follow-up was $3 / 2$ years. The results showed that the subunit adjuvanted vaccine reduced the incidence of herpes zoster in this age group by $97.2 \%$ with an adequate safety profile. The results of a similar study with individuals 70 years and older is pending. This vaccine is not yet licensed by the FDA but looks to be an exciting addition to our interventions against herpes zoster.

\section{Summary}

The majority of herpes zoster cases occur among older adults because the incidence of herpes zoster and PHN increases markedly with aging which is related to an age-related decline in the cellular immune response to VZV. Acute herpes zoster pain, other herpes zoster complications (e.g., ophthalmic zoster) and PHN may profoundly affect physical, psychological and social health and reduce quality of life in older people. Clinicians have several tools to prevent and treat these herpes zoster and PHN. Those tools include the zoster vaccines, early antiviral therapy, careful acute pain management, and a number of neuropathic pain treatments. The thoughtful use of these interventions will markedly reduce the suffering of older adults from herpes zoster and PHN.

\section{Acknowledgments}

This work was supported by the Durham VA Medical Center Geriatric Research, Education and Clinical Center (GRECC) and Duke Pepper Older Americans Independence Center NIA P30 AG028716

\section{References}

1. Cohen JI. The varicella-zoster virus genome. Curr Top Microbiol Immunol. 2010; 342:1-14. [PubMed: 20225013] 
2. Yawn BP, Saddier P, Wollan PC, et al. A population-based study of the incidence and complication rates of herpes zoster before zoster vaccine introduction. Mayo Clin Proc. 2007; 82:1341-1349. [PubMed: 17976353]

3. Pinchinat S, Cebrian-Cuenca AM, Bricout H, et al. Similar herpes zoster incidence across Europe: results from a systematic literature review. BMC Infectious Diseases. 2013; 13:170. [PubMed: 23574765]

4. Oxman MN, Levin MJ, Johnson GR, et al. A vaccine to prevent herpes zoster and postherpetic neuralgia in older adults. N Engl J Med. 2005; 352:2271-84. [PubMed: 15930418]

5. Harpaz R, Ortega-Sanchez IR, Seward JF, Advisory Committee on Immunization Practices (ACIP) Centers for Disease Control and Prevention (CDC). Prevention of herpes zoster: recommendations of the Advisory Committee on Immunization Practices (ACIP). MMWR Recomm Rep. 2008; 57:RR-5.

6. Cohen JI. Herpes Zoster N Engl J Med. 2013; 369:255-263. [PubMed: 23863052]

7. Yawn BP, Wollan PC, Kurland MJ, et al. Herpes zoster recurrences more frequent than previously reported. Mayo Clinic Proceedings. 2011; 86:88-93. [PubMed: 21220354]

8. Tseng HF, Chi M, Smith N, et al. Herpes zoster vaccine and the incidence of recurrent herpes zoster in an immunocompetent elderly population. J Infect Dis. 2012; 206:190-6. [PubMed: 22669900]

9. Winthrop KL, Baddley JW, Chen L, et al. Association between the initiation of anti-tumor necrosis factor therapy and the risk of herpes zoster. JAMA. 2013; 309:887-895. [PubMed: 23462785]

10. Schmader KE, George LK, Hamilton JD. Racial differences in the occurrence of herpes zoster. J Infect Dis. 1995; 171:701-5. [PubMed: 7876622]

11. Zhang JX, Joesoef RM, Bialek S, et al. Association of physical trauma with risk of herpes zoster among Medicare beneficiaries in the United States. J Infect Dis. 2013; 207:1007-11. [PubMed: 23307932]

12. Hales CM, Harpaz R, Joesoef MR, et al. Examination of links between herpes zoster incidence and childhood varicella vaccination. Ann Intern Med. 2013; 159:739-45. [PubMed: 24297190]

13. Viner K, Perella D, Lopez A, et al. Transmission of varicella zoster virus from individuals with herpes zoster or varicella in school and day care settings. J Infect Dis. 2012; 205:1336-41. [PubMed: 22454467]

14. Katz J, Cooper EM, Walther RR, et al. Acute pain in herpes zoster and its impact on health-related quality of life. Clin Infect Dis. 2004; 39:342-8. [PubMed: 15307000]

15. Schmader KE, Sloane R, Pieper C, et al. The impact of acute herpes zoster pain and discomfort on functional status and quality of life in older adults. Clin J Pain. 2007; 23:490-497. [PubMed: 17575488]

16. Jung BF, Johnson RW, Griffin DR, et al. Risk factors for postherpetic neuralgia in patients with herpes zoster. Neurology. 2004; 62:1545-51. [PubMed: 15136679]

17. Harbecke R, Oxman MN, Arnold BA, et al. A real-time PCR assay to identify and discriminate among wild-type and vaccine strains of varicella-zoster virus and herpes simplex virus in clinical specimens, and comparison with the clinical diagnoses. J Med Virol. 2009; 81:1310-22. [PubMed: 19475609]

18. Dworkin RH, Johnson RW, Breuer J, et al. Recommendations for the management of herpes zoster. Clin Infect Dis. 2007; 44:S1-S26. [PubMed: 17143845]

19. Dworkin RH, Barbano RL, Tyring SK, et al. A randomized, placebo-controlled trial of oxycodone and of gabapentin for acute pain in herpes zoster. Pain. 2009; 142:209-17. [PubMed: 19195785]

20. Esmann V, Geil JP, Kroon S, et al. Prednisolone does not prevent postherpetic neuralgia. Lancet. 1987; 2:126-9. [PubMed: 2885599]

21. Wood MJ, Johnson RW, McKendrick MW, et al. A randomized trial of acyclovir for 7 days or 21 days with and without prednisolone for treatment of acute herpes zoster. N Engl J Med. 1994; 330:896-900. [PubMed: 8114860]

22. Whitley RJ, Weiss H, Gnann JW, et al. Acyclovir with and without prednisone for the treatment of herpes zoster: a randomized, placebo-controlled trial. Ann Intern Med. 1996; 125:376-83. [PubMed: 8702088]

23. Berry JD, Petersen KL. A single dose of gabapentin reduces acute pain and allodynia in patients with herpes zoster. Neurology. 2005; 65:444-7. [PubMed: 16087911] 
24. Van Wijck AJM, Opstelten W, Moons KG, et al. The PINE study of epidural steroids and local anaesthetics to prevent postherpetic neuralgia: a randomised controlled trial. Lancet. 2006; 367:219-24. [PubMed: 16427490]

25. Johnson RW, Rice AS. Postherpetic Neuralgia. N Engl J Med. 2014; 371:1526-33. [PubMed: 25317872]

26. NICE Clinical Guideline 173. Neuropathic pain — pharmacological management: the pharmacological management of neuropathic pain in adults in non-specialist settings. National Institute for Health and Care Excellence; London: 2013. http://guidance.nice.org.uk/CG173

27. Dworkin RH, O'Connor AB, Audette J, et al. Recommendations for the pharmacological management of neuropathic pain: an overview and literature update. Mayo Clin Proc. 2010; 85(Suppl):S3-S14. [PubMed: 20194146]

28. Watson CPN, Vernich L, Chipman M, et al. Nortriptyline versus amitriptyline in postherpetic neuralgia: a randomized trial. Neurology. 1998; 51:1166-71. [PubMed: 9781549]

29. Raja SN, Haythornthwaite JA, Pappagallo M, et al. Opioids versus antidepressants in postherpetic neuralgia: a randomized, placebo-controlled trial. Neurology. 2002; 59:1015-21. [PubMed: 12370455]

30. Gilron I, Bailey JM, Tu D, et al. Morphine, gabapentin, or their combination for neuropathic pain. New Engl J Med. 2005; 352:1324-34. [PubMed: 15800228]

31. Gilron I, Bailey JM, Tu D, et al. Nortriptyline and gabapentin, alone and in combination for neuropathic pain: a double-blind, randomised controlled crossover trial. Lancet. 2009; 374:12521261. [PubMed: 19796802]

32. Weiner DK, Schmader KE. Postherpetic pain: more than sensory neuralgia? Pain Medicine. 2006; 7:243-9. [PubMed: 16712624]

33. Oxman MN, Levin MJ, Johnson GR, et al. for the Shingles Prevention Study Group. A vaccine to prevent herpes zoster and postherpetic neuralgia in older adults. N Engl J Med. 2005; 352:227184. [PubMed: 15930418]

34. Tseng HF, Smith N, Harpaz R, et al. Herpes Zoster Vaccine in Older Adults and the Risk of Subsequent Herpes Zoster Disease. JAMA. 2011; 305:160-166. [PubMed: 21224457]

35. Langan SM, Smeeth L, Margolis D, et al. Herpes zoster vaccine effectiveness against incident herpes zoster and post-herpetic neuralgia in an older US population: a cohort study. PLoS Medicine / Public Library of Science. 2013; 10(4):e1001420.

36. Schmader KE, Johnson GR, Saddier P, et al. Effect of a Zoster Vaccine on Herpes Zoster-Related Interference with Functional Status and Health-Related Quality of Life Measures in Older Adults. J Am Geriatric Soc. 2010; 58:1634-41.

37. Tseng HF, Tartof S, Harpaz R, et al. Vaccination against zoster remains effective in older adults who later undergo chemotherapy. Clin Infect Dis. 2014; 59:913-9. [PubMed: 25097079]

38. Simberkoff MS, Arbeit RD, Johnson GR, et al. for the Shingles Prevention Study Group. Safety of the herpes zoster vaccine in the Shingles Prevention Study: a randomized trial. Ann Intern Med. 2010; 152:545-54. [PubMed: 20439572]

39. Tseng HF, Liu A, Sy L, et al. Safety of zoster vaccine in adults from a large managed-care cohort: a Vaccine Safety Datalink study. J Intern Med. 2012; 271:510-520. [PubMed: 22026504]

40. Schmader KE, Oxman MN, Levin MJ, et al. for the Shingles Prevention Study Group. Persistence of the efficacy of zoster vaccine in the shingles prevention study and the short-term persistence substudy. Clin Infect Dis. 2012; 55:1320-8. [PubMed: 22828595]

41. Morrison VA, Oxman MN, Johnson G, et al. Long-Term Persistence of Zoster Vaccine Efficacy. Clin Infect Dis. 2015; 60:900-909. [PubMed: 25416754]

42. Schmader KE, Levin MJ, Gnann JW, et al. Efficacy, safety, tolerability of herpes zoster vaccine in persons 50-59 years of age. Clin Infect Dis. 2012; 54:922-8. [PubMed: 22291101]

43. Hales CM, Harpaz R, Ortega-Sanchez I, et al. Update on Recommendations for Use of Herpes Zoster Vaccine. MMWR. 2014; 63(33):729-731. [PubMed: 25144544]

44. Lal H, Cunningham AL, Godeaux O, et al. Efficacy of an Adjuvanted Herpes Zoster Subunit Vaccine in Older Adults. N Engl J Med. 2015 DOI: 10.1056/NEJMoa1501184. 


\section{Key Points}

The strongest risk factors for herpes zoster are aging and suppression of cellular immunity. The increase in the likelihood of herpes zoster with aging starts around 50 to 60 years of age and increases markedly into late life.

Laboratory diagnostic testing is indicated when differentiating herpes zoster from HSV, for suspected organ involvement, and for atypical presentations, particularly in the immunocompromised host. Polymerase chain reaction (PCR) is the preferred diagnostic test.

The goal of the treatment of herpes zoster in older adults is to decrease the length of the acute attack and to reduce pain by the use of early antiviral therapy (acyclovir, famciclovir, valacyclovir), scheduled analgesia, and if the pain is not adequately controlled, adjunctive agents.

Lidocaine patch 5\%, gabapentin, pregabalin, opioids and tricyclic antidepressants constitute first-line therapies for the management of PHN.

The live attenuated zoster vaccine is recommended for all immunocompetent adults 60 years of age and older by the Advisory Committee on Immunization Practices (ACIP), CDC for the prevention of herpes zoster and PHN. 


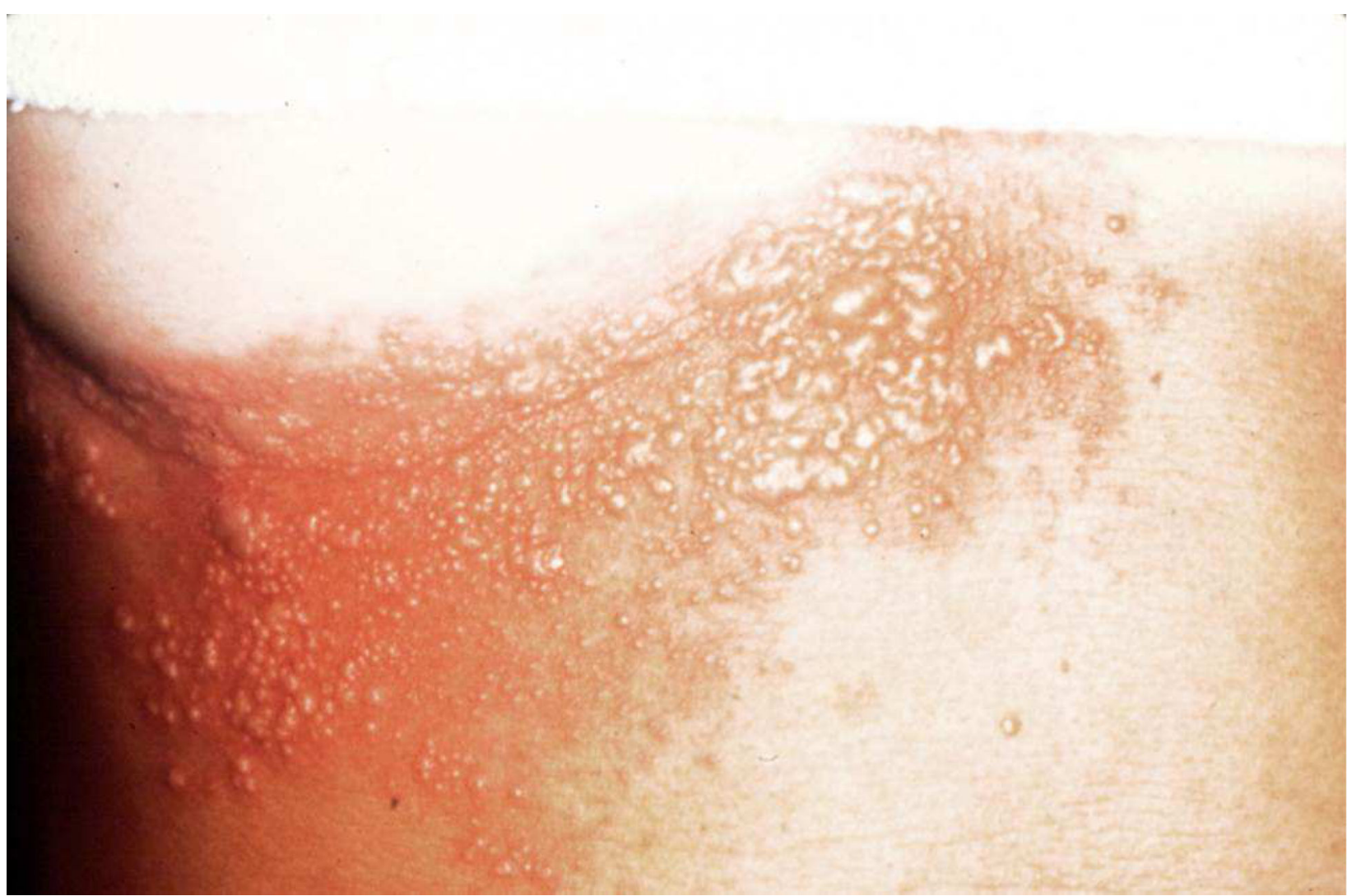

Figure 1.

Herpes zoster rash. 
Table 1

Oral Anti-Varicella-Zoster Virus Medications for Herpes zoster (US)

\begin{tabular}{|c|c|c|c|}
\hline Characteristic & Acyclovir & Valacyclovir & Famciclovir \\
\hline Structure & Deoxyguanosine analog & Valine ester of acyclovir & $\begin{array}{l}\text { Diacetyl 6-deoxy analog of } \\
\text { penciclovir, a deoxyguanosine analog }\end{array}$ \\
\hline Active Agent & Acyclovir & Acyclovir & Penciclovir \\
\hline Oral Bioavailability & $10-20 \%$ & $54 \%$ & $77 \%$ \\
\hline Standard Dosing & $\begin{array}{l}800 \mathrm{mg} \text { every } 4 \text { hrs. (five times a } \\
\text { day) for } 7 \text { days }\end{array}$ & $\begin{array}{l}1 \text { gm every } 8 \text { hrs. (three times a day) } \\
\text { for } 7 \text { days }\end{array}$ & $\begin{array}{l}500 \mathrm{mg} \text { every } 8 \text { hrs. (three times a } \\
\text { day) for } 7 \text { days }\end{array}$ \\
\hline Renal Dosing & $\begin{array}{l}\mathrm{CrCl} 225 \mathrm{ml} / \mathrm{min} \text {, no adjustment } \\
\mathrm{CrCl} 10-24 \mathrm{ml} / \mathrm{min}: 800 \mathrm{mg} \text { every } 8 \\
\text { hrs. } \\
\mathrm{CrCl}<10 \mathrm{ml} / \mathrm{min}: 800 \mathrm{mg} \text { every } 12 \\
\text { hrs. }\end{array}$ & $\begin{array}{l}\mathrm{CrCl} \geq 50 \mathrm{ml} / \mathrm{min} \text { : no dosage } \\
\text { adjustment } \\
\mathrm{CrCl} 30-49 \mathrm{ml} / \mathrm{min}: 1 \mathrm{~g} \text { every } 12 \\
\text { hrs. } \\
\mathrm{CrCl} 10-29 \mathrm{ml} / \mathrm{min}: 1 \mathrm{~g} \text { every } 24 \\
\mathrm{hrs} \text {. } \\
\mathrm{CrCl}<10 \mathrm{ml} / \mathrm{min}: 500 \mathrm{mg} \text { every } 24 \\
\mathrm{hrs} .\end{array}$ & $\begin{array}{l}\mathrm{CrCl}>=60 \mathrm{ml} / \mathrm{min}: \text { no dosage } \\
\text { adjustment } \\
\mathrm{CrCl} 40-59 \mathrm{ml} / \mathrm{min}: 500 \mathrm{mg} \text { every } \\
12 \mathrm{hrs} \text {. } \\
\mathrm{CrCl} 20-39 \mathrm{ml} / \mathrm{min}: 500 \mathrm{mg} \text { every } \\
24 \mathrm{hrs} \text {. } \\
\mathrm{CrCl}<20 \mathrm{ml} / \mathrm{min}: 250 \mathrm{mg} \text { every } 24 \\
\mathrm{hrs} \text {. }\end{array}$ \\
\hline $\begin{array}{l}\text { Benefit: Pain } \\
\text { Median Days to } \\
\text { Resolution, Drug } \\
\text { Vs. Control }(8,11 \text {, } \\
\text { 12) }\end{array}$ & 41 vs. 101 (placebo) & 38 vs. 51 (acyclovir) & 63 vs. 163 (placebo) \\
\hline Adverse Events & Nausea/vomiting, headache, diarrhea & Nausea/vomiting, headache, diarrhea & Nausea/vomiting, headache, diarrhea \\
\hline How Supplied & $\begin{array}{l}200 \mathrm{mg} \text { capsules; } 200,400,800 \mathrm{mg} \\
\text { tablets; } 200 \mathrm{mg} / 5 \mathrm{ml} \text { solution }\end{array}$ & $500 \mathrm{mg}, 1 \mathrm{gm}$ tablets & 125,250 and $500 \mathrm{mg}$ tablets \\
\hline
\end{tabular}




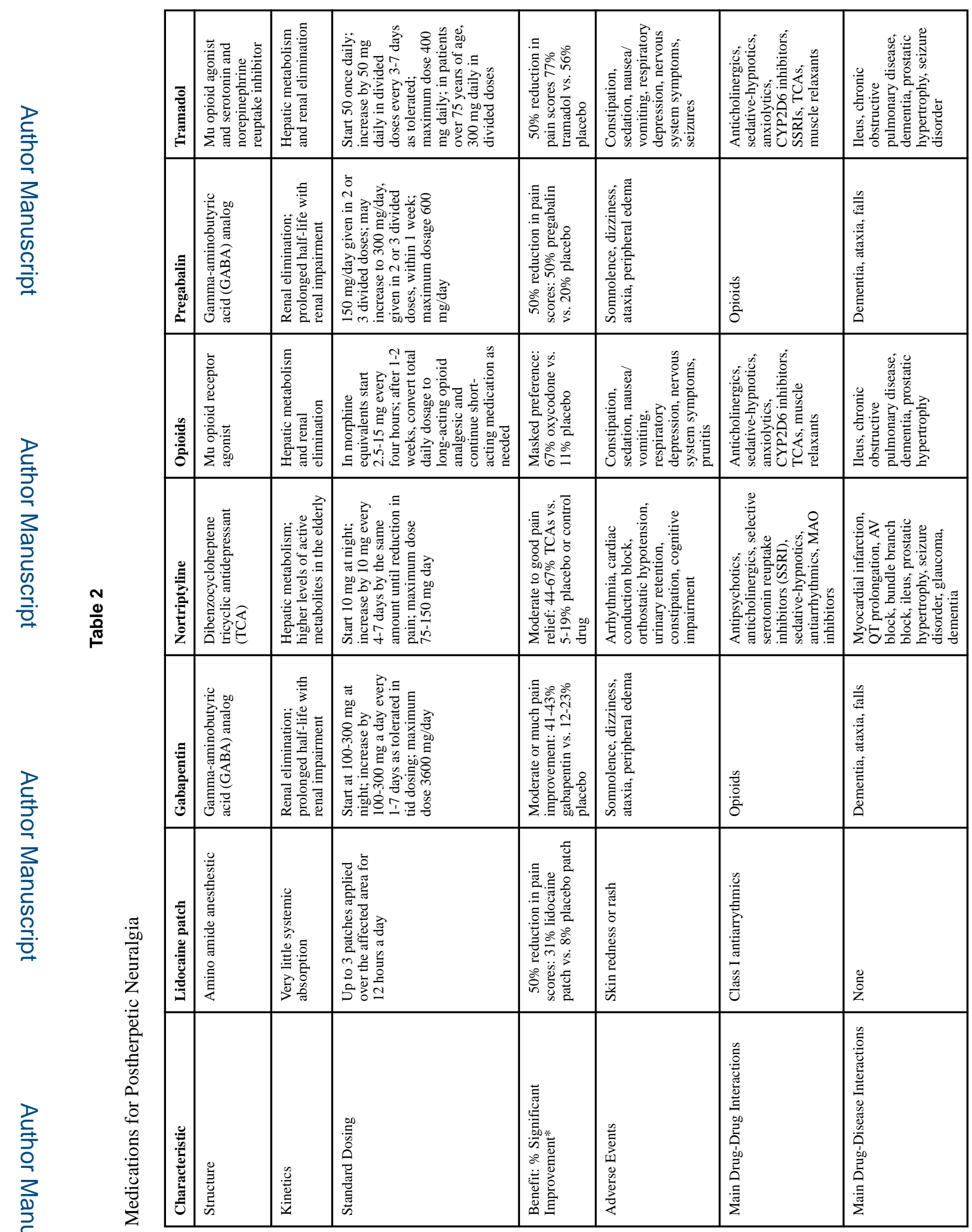

Clin Geriatr Med. Author manuscript; available in PMC 2016 May 06. 


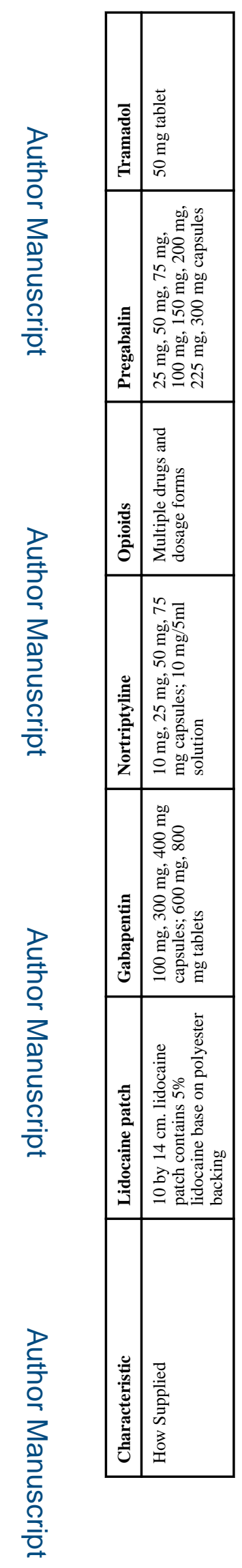

